\title{
Aerobic training as a means to enhance inhibition: what's yet to be studied?
}

\author{
Oron Levin ${ }^{1 *}$ and Yael Netz ${ }^{2}$
}

\begin{abstract}
Some of the neurodegenerative processes in healthy aging, including changes in structural and biochemical properties of the brain, are argued to affect cortical inhibitory functions. Age-related deficits in the ability to control cerebral inhibition may explain wide range of motor and cognitive deficits that healthy older adults experience in daily life such as impaired coordination skills and declines in attention, concentration, and learning abilities. Importantly, evidence from many studies suggests that impaired inhibitory control in advancing age can be delayed or even alleviated by aerobic exercise training. Findings from a recent study by Duchesne and colleagues (2015) may provide insights into this process. First, observations from Duchesne et al. indicated that aerobic exercise training program improved cognitive inhibitory functioning in both patients with Parkinson's disease (PD) and matched older controls. Second, Duchesne et al. showed that cognitive inhibition and motor skills were highly correlated both pre- and post-exercise in PD but not in controls. Based on the aforementioned findings we highlight possible mechanisms that may play a role in the interactions between cognitive and motor inhibitory functions in healthy elderly that could benefit from aerobic exercise training: specifically, the brain neurotransmission systems and the frontal-basal ganglia network. In conclusion, we raise two fundamental questions which are yet to be addressed: (1) the extent to which different brain neurotransmitter systems are affected by aerobic exercise training; (2) the extent to which neurotransmitter levels prior to the onset of intervention may facilitate (or impede) training-induced neuroplasticity in the aging brain.
\end{abstract}

Keywords: Aging, Inhibition, Aerobic exercise training, Brain neurotransmitters, Brain networks, Motor control

\section{Background}

Inhibition plays a critical role in control of many cognitive and motor functions [1-3]. Cognitive inhibition can be conceptualized as a process that blocks the spread of activation, keeping attention focused sharply on the task at hand [2]. Motor inhibition is required during withdrawing, cancelation, or selection of voluntary movements [1, 3]. Although distinct, cognitive and motor inhibitory functions are mediated by overlapping prefrontal brain networks $[4,5]$ which are compromised by aging processes to a greater extent than other regions of the brain [6]. Over the last two decades evidence has accumulated regarding the beneficial effect of aerobic

\footnotetext{
* Correspondence: oron.levin@faber.kuleuven.be

${ }^{1}$ Movement Control and Neuroplasticity Research Group, Department of Kinesiology, Group Biomedical Sciences, KU Leuven Tervuursevest 101, bus 1501, B-3001 Leuven, Belgium

Full list of author information is available at the end of the article
}

exercise training on brain functions and inhibitory control in elderly [7-12]; see reviews [13-15]. The possibility that aerobic exercise training may lead to more efficient inhibitory processes is of particular interest, given that degraded ability for inhibitory control is a primary cause of declined performance in both cognitive and motor tasks in older age $[16,17]$; see reviews $[18,19]$.

The beneficial effect of aerobic exercise training on both cognitive and motor functioning has been recently examined by Duchesne and colleagues [20] on group of patients with Parkinson's disease (PD) and healthy older adults. Findings from this study indicate that besides improving physical fitness, the 3-months aerobic exercise training improved cognitive functioning and motor learning skills in both groups; particularly, enhancing participant's inhibition capacity. For PDs, the baseline performance was differentially associated with trainingrelated improvements in both cognitive and motor domains in the post-tests. While the study did not focus 
specifically on inhibitory functions, its findings offer a platform for understanding the mutual effect of aerobic exercise training on cognitive and motor functioning in elderly as well as their relationships. In the present commentary we focus, specifically, on neurophysiological mechanisms associated with age-related changes in the regulation of inhibition and discuss a multimodal approach to further our knowledge on the influence of aerobic exercise training on (motor) behavior.

\section{The neurophysiological basis of age-related changes in inhibitory control}

Aging gives rise to structural and neurochemical changes in the central nervous system (CNS) that could impair connectivity within and between local and distributed brain networks, leading to cognitive and motor declines $[21,22]$. Structural changes are normally characterized by a decrease in white matter microstructural organization [21-25] and gray matter loss [26-28]. Structural declines may occur in parallel with depletion in the concentrations of regional levels of neurotransmitters such as gamma-aminobutyric acid (GABA) [29, 30] and serotonin [31-35]; see review [36]. Deficiencies in GABAergic activity [37-39] and impaired interactions between GABAergic and cholinergic system [40, 41] have been documented, for example, in healthy aging and older adults with mild cognitive impairments who also demonstrated deficient motor inhibition; see review [19].

Movement control requires integration of information from various sensory sources (vision, proprioception, tactile) which is critically dependent on the balance between excitatory and inhibitory processes in the brain. This balance is expected to be perturbed by impaired activation of the above mentioned neurotransmission systems [34, 39] or disruption in connectivity between specific brain substructures [21, 22]. While all healthy older individuals tend to present general declines in both structural and biochemical properties of the brain $[21-25,29,32,33,37-41]$, performance declines may still not be evident in some individuals due to compensatory recruitment of alternative brain resources [17, 42-44]. The conditions and functions of principal brain neurotransmitter systems and their age- and/or pathology-related alterations can be studied via application of a multimodal approach that combines an array of brain imaging and brain stimulation techniques $[15,19]$. For example, assessment of neurochemical properties (i.e., neurotransmitter concentrations and concentration ratios) in specific brain regions can be monitored with magnetic resonance spectroscopy (MRS) [29, 39] or positron emission tomography (PET) [32] whereas the effects of local neurotransmitter levels for cortical inhibitory processes and neurophysiological assessments of brain network activity and connectivity can be studied with functional magnetic resonance imaging (fMRI) and/or transcranial magnetic stimulation [16, 17, 37-44]; see reviews $[18,19,45]$.

\section{The prefrontal-basal ganglia network}

Inhibitory functions are believed to be largely subserved by the frontal lobes of the brain. The role of these brain regions in the inhibitory control of action and cognition is well documented [46, 47]; see reviews [1, 48]). Notably, parts of the brain network that regulate inhibition are located in the prefrontal cortex which is more prone to age-related structural changes than posterior areas [23]. Evidence for the involvement of the prefrontalbasal ganglia network in cognitive and motor functioning has been demonstrated by Duchesne et al. [20], showing positive relationship between cognitive and motor abilities in PD individuals. Indeed, recent structural imaging studies clearly show that age-related changes in the microstructural organization of the prefrontal-basal ganglia network are associated with a reduced ability to actively prevent movements when a "stop" is delivered after a "go" $[49,50]$. Crucially, agerelated changes in brain activity and connectivity are often seen in prefrontal brain regions such as the dorsolateral prefrontal cortex (DLPFC), inferior frontal cortex (IFC), and/or pre-supplementary motor area (pre-SMA) $[42,43]$ that are classically involved in the suppression of prepotent response tendencies.

Another interesting finding from the study of Duchesne and colleagues [20] was that baseline cognitive performance of PD individuals was positively associated with training-related improvements in both cognitive flexibility and inhibition. This observation suggests that the ability of PDs to improve their motor and/or cognitive skills is determined, largely, by the integrity of the prefrontal network. Taken together, observations from Duchesne et al. [20] call for further investigation of the effect of aerobic exercise training on the functioning of the aging prefrontal-basal ganglia network.

\section{Conclusions}

Duchesne et al. [20] proposed that "aerobic exercise training can be a valuable non-pharmacological intervention to promote physical fitness in early $P D$, but also better cognitive and procedural functioning". Their findings suggest that aerobic exercise training can at least partly improve and/or restore functionality of dopaminergic system in patients with PD and prompt questions about the effect of aerobic exercise training on the interactions between cognitive and motor functioning. Principal challenges for future research at this juncture are: (1) to examine how other brain neurotransmitter systems are affected by aerobic exercise training; (2) to investigate the 
extent to which long-term effects of aerobic exercise training on cognitive and motor inhibitory functions (and their interactions) are determine by the integrity of prefrontal neurotransmitter systems; specifically but not exclusively: GABA, serotonin, and dopamine. The addition of a neurochemical perspective to the study of brain function and neuroplasticity is highly innovative and would allow a deeper understanding of mechanisms by which aerobic exercise training acts on cerebral inhibitory processes.

Another principal challenge is to examine whether beneficial effects on cognitive/motor functioning could be further enhanced by combining aerobic exercise training with other types interventions such as pharmacological interventions [30], or non-invasive brain stimulation techniques [51]; the latter may be used to target specific brain structures or neurotransmitter systems. Finally, the fact that older adults can improve inhibitory control through a multiple exercise intervention (i.e., aerobic exercise training combined with the practice of motor/cognitive tasks) even more than through a single exercise intervention (i.e., aerobic exercise training alone) is well documented [52-55]. Future research should work to established to what extent these interventions affect brain regions or networks that regulate inhibition (in association with their effects on motor functioning, cognitive functioning, and health [56]). A critical aim in this respect is to explore the specific effects of each intervention (or combination of interventions) on brain-behavior relationships.

\section{Competing interests}

None of the authors have any competing interests in the manuscript.

\section{Authors' contributions}

Both authors read and approved the final manuscript.

\section{Acknowledgments}

This work was supported by KU Leuven Research Fund Grant (C16/15/070), Flanders Fund for Scientific Research (FWO) Grants (G0721.12, G0708.14), the Interuniversity Attraction Poles Program initiated by the Belgian Science Policy Office (P7/11), and the European Group for Research into Elderly and Physical Activity (EGREPA).

\section{Author details}

'Movement Control and Neuroplasticity Research Group, Department of Kinesiology, Group Biomedical Sciences, KU Leuven Tervuursevest 101, bus 1501, B-3001 Leuven, Belgium. 'Zinman College for Physical Education and Sport Sciences, Wingate Institute, Netanya, Israel.

Received: 10 November 2015 Accepted: 22 December 2015 Published online: 24 December 2015

\section{References}

1. Aron AR. The neural basis of inhibition in cognitive control. Neuroscientist. 2007;13:214-28.

2. Diamond A. Executive functions. Annu Rev Psychol. 2013;64:135-68.

3. Stinear CM, Coxon JP, Byblow WD. Primary motor cortex and movement prevention: where Stop meets Go. Neurosci Biobehav Rev. 2009;33:662-73.

4. Godefroy O, Cabaret M, Petit-Chenal V, Pruvo JP, Rousseaux M. Control functions of the frontal lobes. Modularity of the central-supervisory system? Cortex. 1999;35:1-20.
5. Sylvester CY, Wager TD, Lacey SC, Hernandez L, Nichols TE, Smith EE, et al. Switching attention and resolving interference: fMRI measures of executive functions. Neuropsychologia. 2003;41:357-70.

6. Raz N, Gunning-Dixon FM, Head D, Dupuis JH, Acker JD. Neuroanatomical correlates of cognitive aging: evidence from structural magnetic resonance imaging. Neuropsychology. 1998;12:95-114.

7. Dustman RE, Emmerson RY, Ruhling RO, Shearer DE, Steinhaus LA, Johnson SC, et al. Age and fitness effects on EEG, ERPs, visual sensitivity, and cognition. Neurobiol Aging. 1990;11:193-200.

8. McGregor KM, Zlatar Z, Kleim E, Sudhyadhom A, Bauer A, Phan S, et al. Physical activity and neural correlates of aging: a combined TMS/fMRI study. Behav Brain Res. 2011;222:158-68.

9. McGregor KM, Heilman KM, Nocera JR, Patten C, Manini TM, Crosson B, et al. Aging, aerobic activity and interhemispheric communication. Brain Sci. 2012;2:634-48.

10. McGregor KM, Nocera JR, Sudhyadhom A, Patten C, Manini TM, Kleim JA, et al. Effects of aerobic fitness on aging-related changes of interhemispheric inhibition and motor performance. Front Aging Neurosci. 2013;5:66.

11. Voss MW, Nagamatsu LS, Liu-Ambrose T, Kramer AF. Exercise, brain, and cognition across the life span. J App Physiol. 2011;111:1505-13.

12. Voss MW, Prakash RS, Erickson Kl, Basak C, Chaddock L, Kim JS, et al. Plasticity of brain networks in a randomized intervention trial of exercise training in older adults. Front Aging Neurosci. 2011;2:32.

13. Kramer AF, Erickson KI. Effects of physical activity on cognition, well-being, and brain: human interventions. Alzheimers Dement. 2007;(2 Suppl):S45-51.

14. Kaliman P, Párrizas M, Lalanza JF, Camins A, Escorihuela RM, Pallàs M. Neurophysiological and epigenetic effects of physical exercise on the aging process. Ageing Res Rev. 2011;10:475-86.

15. Voelcker-Rehage C, Niemann C. Structural and functional brain changes related to physical activity in different age groups. Neurosci Biobehav Rev. 2013;37:2268-95.

16. Fling BW, Seidler RD. Fundamental differences in callosal structure, neurophysiologic function, and bimanual control in young and older adults. Cereb Cortex. 2012;22:2643-52.

17. Nielson KA, Langenecker SA, Garavan H. Differences in the functional neuroanatomy of inhibitory control across the adult life span. Psychol Aging. 2002;17:56-71.

18. Turner GR, Spreng RN. Executive functions and neurocognitive aging: dissociable patterns of brain activity. Neurobiol Aging. 2012;33:826.e1-e13.

19. Levin O, Fujiyama H, Boisgontier MP, Swinnen SP, Summers JJ. Aging and motor inhibition: a converging perspective provided by brain stimulation and imaging approaches. Neurosci Biobehav Rev. 2014;43:100-17.

20. Duchesne C, Lungu O, Nadeau A, Robillard ME, Boré A, Bobeuf F, et al. Enhancing both motor and cognitive functioning in Parkinson's disease: aerobic exercise as a rehabilitative intervention. Brain Cogn. 2015;99:68-77.

21. Langan J, Peltier SJ, Bo J, Fling BW, Welsh RC, Seidler RD. Functional implications of age differences in motor system connectivity. Front Sys Neurosci. 2010;4:17.

22. O'Sullivan M, Jones DK, Summers PE, Morris RG, Williams SC, Markus HS Evidence for cortical "disconnection" as a mechanism of age-related cognitive decline. Neurology. 2000;57:632-8.

23. Pfefferbaum A, Adalsteinsson E, Sullivan EV. Frontal circuitry degradation marks healthy adult aging: Evidence from diffusion tensor imaging. Neuroimage. 2005;26:891-9.

24. Salat DH, Tuch DS, Greve DN, van der Kouwe AJ, Hevelone ND, Zaleta AK, et al. Age-related alterations in white matter microstructure measured by diffusion tensor imaging. Neurobiol Aging. 2005;26:1215-27.

25. Sullivan EV, Adalsteinsson E, Hedehus M, Ju C, Moseley M, Lim KO, et al. Equivalent disruption of regional white matter microstructure in ageing healthy men and women. Neuroreport. 2001;12:99-104.

26. Good CD, Johnsrude IS, Ashburner J, Henson RN, Friston KJ, Frackowiak RS A voxel-based morphometric study of ageing in 465 normal adult human brains. Neuroimage. 2001;14:21-36.

27. Resnick SM, Pham DL, Kraut MA, Zonderman AB, Davatzikos C. Longitudinal magnetic resonance imaging studies of older adults: a shrinking brain. J Neurosci. 2003;23:3295-301.

28. Ziegler G, Dahnke R, Jancke L, Yotter RA, May A, Gaser C. Brain structural trajectories over the adult lifespan. Hum Brain Mapp. 2012;33:2377-89.

29. Gao F, Edden RA, Li M, Puts NA, Wang G, Liu C, et al. Edited magnetic resonance spectroscopy detects an age-related decline in brain GABA levels. Neuroimage. 2013;78:75-82. 
30. Leventhal AG, Wang YC, Pu ML, Zhou YF, Ma YY. GABA and its agonists improved visual cortical function in senescent monkeys. Science. 2003;300:812-5.

31. Birthelmer A, Stemmelin J, Jackisch R, Cassel JC. Presynaptic modulation of acetylcholine, noradrenaline, and serotonin release in the hippocampus of aged rats with various levels of memory impairments. Brain Res Bull. 2003;60:283-96.

32. Goldberg S, Smith GS, Barnes A, Ma Y, Kramer E, Robeson K, et al. Serotonin modulation of cerebral glucose metabolism in normal aging. Neurobiol Aging. 2004;25:167-74.

33. Lamar M, Cutter WJ, Rubia K, Brammer M, Daly EM, Craig MC, et al. 5-HT, prefrontal function and aging: $\mathrm{fMRI}$ of inhibition and acute tryptophan depletion. Neurobiol Aging. 2009;30:1135-46.

34. Passamonti L, Crockett MJ, Apergis-Schoute AM, Clark L, Rowe JB, Calder AJ, et al. Effects of acute tryptophan depletion on prefrontal-amygdala connectivity while viewing facial signals of aggression. Biol Psychiatry. 2012;71:36-43

35. Sibille E, Su J, Leman S, Le Guisquet AM, Ibarguen-Vargas Y, Joeyen-Waldorf J, et al. Lack of serotonin1B receptor expression leads to age-related motor dysfunction, early onset of brain molecular aging and reduced longevity. Mol Psychiatry. 2007:12:1042-56. 975.

36. Mendelsohn D, Riedel WJ, Sambeth A. Effects of acute tryptophan depletion on memory, attention and executive functions: A systematic review. Neurosci Biobehav Rev. 2009;33:926-52.

37. Fujiyama H, Garry MI, Levin O, Swinnen SP, Summers JJ. Age-related differences in inhibitory processes during interlimb coordination. Brain Res. 2009; 1262:38-47.

38. Heise KF, Zimerman M, Hoppe J, Gerloff C, Wegscheider K, Hummel FC. The aging motor system as a model for plastic changes of GABA-mediated intracortical inhibition and their behavioral relevance. J Neurosci. 2013;33:9039-49.

39. Kapogiannis D, Reiter DA, Willette AA, Mattson MP. Posteromedial cortex glutamate and GABA predict intrinsic functional connectivity of the default mode network. Neuroimage. 2013;64:112-9.

40. Young-Bernier M, Davidson PS, Tremblay F. Paired-pulse afferent modulation of TMS responses reveals a selective decrease in short latency afferent inhibition with age. Neurobiol Aging. 2012;33:835. e831-811.

41. Young-Bernier M, Kamil Y, Tremblay F, Davidson PS. Associations between a neurophysiological marker of central cholinergic activity and cognitive functions in young and older adults. Behav Brain Funct. 2012;8:17.

42. Goble DJ, Coxon JP, Van Impe A, De Vos J, Wenderoth N, Swinnen SP. The neural control of bimanual movements in the elderly: brain regions exhibiting age-related increases in activity, frequency-induced neural modulation, and task-specific compensatory recruitment. Hum Brain Mapp. 2010;31:1281-95

43. Heuninckx S, Wenderoth N, Swinnen SP. Systems neuroplasticity in the aging brain: recruiting additional neural resources for successful motor performance in elderly persons. J Neurosci. 2008;28:91-9.

44. Ward NS. Compensatory mechanisms in the aging motor system. Ageing Res Rev. 2006;5:239-54.

45. Seidler RD, Bernard JA, Burutolu TB, Fling BW, Gordon MT, Gwin JT, et al. Motor control and aging: links to age-related brain structural, functional, and biochemical effects. Neurosci Biobehav Rev. 2010;34:721-33.

46. Aron AR, Poldrack RA. Cortical and subcortical contributions to stop signal response inhibition: role of the subthalamic nucleus. J Neurosci. 2006;26:2424-33.

47. Duann J-R, Ide JS, Luo X, Li CS. Functional connectivity delineates distinct roles of the inferior frontal cortex and presupplementary motor area in stop signal inhibition. J Neurosci. 2009;29:10171-9.

48. Aron AR, Durston S, Eagle DM, Logan GD, Stinear CM, Stuphorn V. Converging evidence for a fronto-basal-ganglia network for inhibitory control of action and cognition. J Neurosci. 2007;27:11860-4.

49. Coxon JP, Goble DJ, Van Impe A, De Vos J, Wenderoth N, Swinnen SP. Reduced basal ganglia function when elderly switch between coordinated movement patterns. Cereb Cortex. 2010;20:2368-79.

50. Coxon JP, Van Impe A, Wenderoth N, Swinnen SP. Aging and inhibitory control of action: cortico-subthalamic connection strength predicts stopping performance. J Neurosci. 2012;32:8401-12.

51. O'Shea J, Boudrias MH, Stagg CJ, Bachtiar V, Kischka U, Blicher JU, et al. Predicting behavioural response to TDCS in chronic motor stroke. Neuroimage. 2014;85:924-33.
52. Greenwood PM, Parasuraman R. Neuronal and cognitive plasticity: a neurocognitive framework for ameliorating cognitive aging. Front Aging Neurosci. 2010;2:150

53. Berryman N, Bherer L, Nadeau S, Lauzière S, Lehr L, Bobeuf F, et al. Multiple roads lead to Rome: combined high-intensity aerobic and strength training vs. gross motor activities leads to equivalent improvement in executive functions in a cohort of healthy older adults. Age. 2014;36:9710.

54. Fabre C, Chamari K, Mucci P, Massé-Biron J, Préfaut C. Improvement of cognitive function by mental and/or individualized aerobic training in healthy elderly subjects. Int J Sports Med. 2002;23:415-21.

55. Shatil E. Does combined cognitive training and physical activity training enhance cognitive abilities more than either alone? A four-condition randomized controlled trial among healthy older adults. Front Aging Neurosci. 2013;5:8.

56. Netz Y, Zijlstra W. EURAPA moves to open access: research trends and challenges in physical activity in old age. Eur Rev Aging Phys Act. 2015;12:1. doi:10.1186/s11556-015-0149-4.

\section{Submit your next manuscript to BioMed Central and we will help you at every step:}

- We accept pre-submission inquiries

- Our selector tool helps you to find the most relevant journal

- We provide round the clock customer support

- Convenient online submission

- Thorough peer review

- Inclusion in PubMed and all major indexing services

- Maximum visibility for your research

Submit your manuscript at www.biomedcentral.com/submit
) Biomed Central 